\title{
Fábrica da nutrição neoliberal: elementos para uma discussão sobre as novas abordagens comportamentais*
}

\author{
I ${ }^{1}$ Cristiane Marques Seixas, ${ }^{2}$ Juliana Pereira Casemiro, \\ ${ }^{3}$ Carolina de Oliveira Coutinho, ${ }^{4}$ Thais Nascimento Conde, ${ }^{5}$ Ana Laura Brandão I
}

Resumo: A aplicação de teorias do comportamento em diversas áreas tem despertado o interesse em investigar como essas teorias são incorporadas pelo campo da Alimentação e Nutrição, problematizando sua interdisciplinaridade. Este artigo busca contextualizar a Nutrição como ciência e seu desenvolvimento num contexto social em que o neoliberalismo opera como sistema de gestão da vida política, econômica e social. Visam-se reunir elementos teóricos relativos à noção de comportamento extraídos do campo da psicologia a fim de contribuir para o aprofundamento das reflexôes acerca da emergência de técnicas baseadas em teorias do comportamento, tais como a Nutrição Comportamental, o Mindful Eating e o Comer Intuitivo, além de apresentar ponderaçôes sobre os limites relacionados à aplicação dessas abordagens na formação e na prática dos profissionais de saúde.

> Palavras-chave: Nutrição Comportamental; Mindful Eating; Comer Intuitivo; neoliberalismo; interdisciplinaridade.

\author{
${ }^{1}$ Instituto de Nutrição, \\ Universidade do Estado do Rio de \\ Janeiro. Rio de Janeiro-RJ, Brasil \\ (cris.marques.seixas@gmail.com). \\ ORCID: 0000-0003-2630-9746 \\ ${ }^{2}$ Instituto de Nutrição, \\ Universidade do Estado do Rio de \\ Janeiro. Rio de Janeiro-RJ, Brasil \\ (julianacasemiro@gmail.com). \\ ORCID: 0000-0001-6940-2479 \\ ${ }^{3}$ Instituto de Nutrição, \\ Universidade do Estado do Rio de \\ Janeiro. Rio de Janeiro-RJ, Brasil \\ (carolocoutinho@hotmail.com). \\ ORCID: 0000-0001-7517-6543 \\ ${ }^{4}$ Instituto de Nutrição, \\ Universidade do Estado do Rio de \\ Janeiro. Rio de Janeiro-RJ, Brasil \\ (thaisnconde@gmail.com). \\ ORCID: 0000-0001-9926-1662 \\ ${ }^{5}$ Escola Nacional de Saúde Pública \\ Sergio Arouca, Fundação Oswaldo \\ Cruz. Rio de Janeiro-RJ, Brasil \\ (alaurabrandao@gmail.com). \\ ORCID: 0000-0002-7148-2268
}

Recebido em: 02/04/2020 Aprovado em: 31/07/2020 Revisado em: 07/10/2020

\footnotetext{
* Este trabalho apresenta resultados preliminares da pesquisa "Obesidade e Transtornos Alimentares: interfaces entre o campo da Alimentação e Nutrição e as abordagens psicológicas e psicanalíticas", financiada pela Universidade do Estado do Rio de Janeiro por meio dos programas Prociência e PIBIC e pela FAPERJ (APQ1 e TCT).
} 


\section{Introdução}

Muitos são os caminhos possíveis para a mudança do comportamento e inúmeras são as teorias que tentam explicar como e por que comportamentos mudam. Nas últimas décadas, o interesse na aplicação dessas teorias nas áreas da saúde, educação, criminologia, economia, energia, clima, entre outras, aumentou consideravelmente, na esperança de que a compreensão da mudança comportamental melhore os serviços oferecidos. Esse desafio vem ganhando espaço nas pesquisas, conformando também um campo científico, o que por si só implica uma disputa entre diferentes modelos e formas de entendimento da problemática em pauta.

No que diz respeito à alimentação não é diferente. Assistimos atônitos à proliferação de abordagens comportamentais no campo da Alimentação e Nutrição como resposta à busca por uma fórmula mágica que permita aos nutricionistas - e outros profissionais de saúde - construir estratégias ditas eficazes e alcançar resultados aparentemente satisfatórios frente aos agravos associados aos chamados maus hábitos alimentares. Para compreender esse fenômeno, é preciso contextualizar a emergência da nutrição como ciência, política social e/ou profissão e seu desenvolvimento ao longo dos últimos anos num contexto social em que o neoliberalismo opera como sistema de gestão da vida econômica e social.

Nesse sentido, o presente ensaio visa reunir elementos teóricos relativos à noção de comportamento extraídos do campo da psicologia, a fim de contribuir para o aprofundamento das reflexôes acerca da emergência de abordagens baseadas em teorias do comportamento e sua relação com o jogo de fabricação do sujeito neoliberal (DARDOT; LAVAL, 2016). Ainda que no campo da Alimentação e Nutrição a ideia de comportamento esteja sendo gradativamente incorporada como um conceito unívoco, na psicologia o mesmo possui contornos polissêmicos fomentando uma densa discussão a partir de diferentes enfoques. Vale destacar que, neste trabalho, faremos um breve recorte dessa discussão tão cara à psicologia sem pretender esgotá-la, apresentando, porém, ponderações sobre os limites relacionados à sua aplicação nas práticas relacionadas à nutrição.

\section{Nutrição, Ciência e Política}

Compreender o momento atual do campo da Alimentação e Nutrição em seu caráter interdisciplinar demanda a contextualização sócio-histórica. Vale situar que 
sua emergência se deu no período entre a Primeira e Segunda Guerras Mundiais, no âmbito da consolidação de uma sociedade capitalista urbano-industrial. É nesse contexto que surgem a Food and Agriculture Organization (FAO), o United Nations International Children's Emergency Fund (UNICEF) e os primeiros centros de pesquisa voltados para a questão da alimentação da população. No Brasil, na esteira de tais acontecimentos e num cenário de consolidação da ciência da Nutrição, surgem os primeiros cursos de graduação em nutrição (VASCONCELOS, 2002) e, na sequência, os primeiros técnicos deste campo e especialistas neste tema.

Com o desenvolvimento científico e as novas demandas de saúde da população, observou-se um desvio do foco da Nutrição inicialmente voltado para os problemas relacionados à fome e à desnutrição para as doenças crônicas não transmissíveis (DCNTs), que passam a configurar um grave problema de saúde pública. Posteriormente, a obesidade aparece no cenário mundial como importante desafio a ser enfrentado. Destaca Poulain (2013) que a obesidade foi declarada epidemia mundial pela Organização Mundial da Saúde (OMS) em 2000 e desde então o quadro vem se agravando. Esse autor sustenta que a obesidade é um problema social e um novo fator de desigualdade em saúde. Por isso mesmo, chama atençáo para os limites da perspectiva científica e para a necessidade de posicionamento também na escala político-administrativa.

Diante deste quadro de crescimento da prevalência da obesidade e das DCNTs, tem se tornado cada vez maior a adesão ao entendimento de que estamos diante de um cenário global que é fruto do intenso processo de expansão do neoliberalismo acompanhado pela propagação das fusôes entre grandes corporaçóes do setor agroalimentício e a consolidação de um sistema alimentar global que oferece quantidades excessivas de alimentos calóricos e ricos em sal, açúcar e gordura (MORIN, 2013; MOSS, 2015).

Pressôes para homogeneização de hábitos alimentares seguem em curso a partir da conivência entre essas grandes corporaçôes e a grande mídia. Esse processo, contudo, não tem sido linear e especialistas, pequenos agricultores e produtores de alimentos, organizaçóes da sociedade civil e até mesmo pessoas comuns têm sido criativos em apresentar formas de resistências.

Foi neste caminho que se tornou inevitável reconhecer a complexidade da Nutrição, bem como a necessidade de ampliar o olhar sobre as análises das práticas alimentares nas diversas partes do mundo. Problemas complexos exigem um pensar 
e agir igualmente complexos para analisar e propor saídas (MORIN, 2011). A interdisciplinaridade, a multiprofissionalidade e a valorização de diferentes saberes despontam como estratégias importantes para as ciências e para a proposição de ações mais adequadas e efetivas. Mas de que maneira e em que medida essa conjugação de saberes e disciplinas tem sido exercida? Qual o rigor metodológico e teórico necessário para que esses encontros disciplinares ultrapassem conexóes superficiais ou apenas utilitárias?

Ainda sob este ângulo, podemos questionar: por que é justamente neste cenário de reconhecimento da complexidade da Nutrição que assistimos à proliferação de discursos e técnicas no campo da Nutrição que (re)colocam na agenda estratégias centradas na responsabilização do indivíduo, no comportamento e no autocontrole? Diante disto, as técnicas comportamentais (Nutrição Comportamental), meditativas (Mindful Eating) e motivacionais ou de racionalização (Comer Intuitivo) estão sob holofotes da grande mídia e tornam-se objeto de desejo de muitos profissionais de saúde - tanto os recém-formados quanto os mais experientes no bojo do crescente esforço de tornarem-se "empreendedores de si" (DARDOT; LAVAL, 2016).

O debate aqui proposto articula elementos teóricos advindos de diferentes campos de conhecimento que precisam interagir conceitualmente, a fim de precisar limites e possibilidades tanto teóricas como práticas e metodológicas. Nesse sentido, vale considerar a abordagens baseadas em teorias do comportamento que florescem no campo da Alimentação e Nutrição em relação ao novo contexto social e biopolítico das sociedades contemporâneas marcadas por uma lógica neoliberal que ultrapassa os limites da economia e da política para se fazer valer no que há de mais íntimo nos indivíduos.

No campo da saúde, onde a Alimentação e a Nutrição estão inseridas, o nutricionista é o profissional que tem a prerrogativa de prescrever uma alimentação adequada e saudável. Apesar disso, as políticas públicas que se desenvolvem no âmbito do Sistema Único de Saúde (SUS) investem na consolidação de uma lógica assistencial que entrelaça especialidades por meio de dispositivos da Estratégia de Saúde da Família, tais como o matriciamento realizado pelas equipes dos Núcleos Ampliados de Saúde da Família (NASFs) e as interconsultas. Além disso, partilha com outros profissionais de saúde a atuação na prevenção de doenças e promoção da qualidade de vida das pessoas, por meio da construção e disseminação de informaçôes sobre a alimentação para a população em geral. Contudo, a divulgação 
de informações sobre alimentação e nutrição tem sido cada vez mais ampla e difusa, tornando-se assim um dos grandes obstáculos para uma alimentação adequada e saudável (BRASIL, 2014a). Isto porque o excesso de informação tem atuado como promotor de incertezas e estresse que terminam por gerar constante necessidade de que um especialista ajude a decidir o que, quando e quanto se deve comer (POLLAN, 2007).

Nesse cenário, pelo menos duas visões sobre o profissional nutricionista são construídas no senso comum: ou ele é o retrógrado, inflexível e autoritário ou ele é moderno, flexível e popular nas redes sociais. Como bom empreendedor, esse segundo tipo de profissional sabe fazer sua autopromoção e tem em seu currículo a "mais nova super-especialidade" do momento. Respeitando a fluidez e velocidade da atual sociedade (BAUMAN, 2001), percebe-se que o que é considerada a "mais nova super-especialidade" de hoje certamente será, em breve, substituída por outra "mais nova super-especialidade". Assim, a cada nova demanda, novos nomes sáo criados para especificar a própria Nutriçáo, carregando sempre um aspecto inovador - como por exemplo, a Nutrição Funcional, a Nutrição Estética, a Nutrição Fitoterápica, a Nutrição Esportiva, a Nutrição Ortomolecular e mais recentemente a Nutrição Comportamental.

Esse processo de "hiperespecialização" (MORIN, 2014, p. 13) que se fecha sobre si mesmo não representa uma novidade. Com a "mais nova super-especialidade", o nutricionista ganha novas conotaçôes profissionais (não necessariamente habilidades ou competências) no mercado de trabalho (e no mercado das dietas) que advêm supostamente de uma ampliação de saberes e de sua integração com outras áreas do conhecimento que trariam à clínica a flexibilidade e variedade de ferramentas que fariam sua prática menos técnica, mais profissional e, consequentemente, mais eficaz. O que é novo, portanto, são as formas de produzir, divulgar e vender esses títulos de especialistas.

Dessa maneira, podemos identificar a redução gradativa da prática do nutricionista a uma atuação que utiliza o conhecimento científico (e até mesmo do senso comum) de modo instrumental, em detrimento dos fundamentos de uma atuação interdisciplinar. A afirmação dessa perspectiva, contudo, capitaliza profissionais e pesquisadores que se mostram afeitos à possibilidade de participação de outros campos de saberes na Nutrição, sem que haja de fato um entrelaçamento epistêmico que afirme a pluralidade do campo e a complexidade do objeto nutrição- 
alimentação (PRADO; MARTINS; CARVALHO, 2018). Podemos considerar, assim que o caráter ainda embrionário da perspectiva interdisciplinar no campo da Alimentação e Nutrição deixa brechas para a emergência de propostas falaciosas que fragilizam ainda mais a consolidação de uma abordagem baseada no cuidado e na valorização dos sujeitos, suas histórias, cultura, memória e afetos.

Nessa brecha inscrevem-se as novas abordagens teóricas que, baseadas em supostas evidências, propõem a incorporação de técnicas comportamentais (Nutrição Comportamental), técnicas meditativas (Mindful Eating) e técnicas motivacionais ou de racionalização (Comer Intuitivo). Essas propostas são o principal foco de interesse da presente reflexáo, pois se mostram, ao fim e ao cabo, como arremedos de teoria, em que os desenvolvimentos conceituais são descontextualizados dos campos teóricos de origem, limitados em sua aplicação prática e visam, em última análise, dar um caráter teórico para experimentaçôes que se baseiam não em evidências científicas, mas em evidências da prática de uma psicologia selvagem (FREUD, 2006).

\section{Mas enfim, como mudar o comportamento?}

Como resultado da busca por novas formas de lidar com os impasses e dificuldades colocadas pelos fracassos na mudança de comportamentos e hábitos, e da disputa de saberes sobre essas mudanças, observa-se, nas últimas décadas, a consolidação de uma distinçâo nas ciências comportamentais entre os modelos de comportamento e as teorias de mudança comportamental (DARNTON, 2008; VAN DER LINDEN, 2013). Nessa perspectiva, os modelos de comportamento são constructos teóricos mais voltados para a compreensão dos fatores psicológicos que explicam ou preveem um comportamento específico, enquanto as teorias da mudança comportamental são elementos mais pragmáticos que visam apoiar intervenções e geralmente objetivam alterar um determinado comportamento. Assim, entender e mudar o comportamento são dois aspectos teóricos distintos, mas que se complementam.

Sabe-se também que para promover uma mudança comportamental bemsucedida é preciso uma compreensão completa dos fatores que influenciam o comportamento, o que implica distinguir os inúmeros fatores que o determinam. Para Dolan et al. (2012), destacam-se sobretudo características ambientais e pessoais. Ainda que não sejam de fato separáveis, as pessoas e o ambiente em que vivem compõem um conjunto que é influenciado diretamente pela subjetividade, pela história e pela cultura de determinada sociedade. 
Vale lembrar que hábitos e comportamentos se formam e se sustentam pelos contextos sociais em que se inscrevem e se desenvolvem, náo podendo ser totalmente separados. Uma tentativa de diferenciá-los é feita por Klotz-Silva et al. (2016) a propósito da distinção entre comportamentos e hábitos alimentares. Para as autoras, se os hábitos alimentares podem ser entendidos como uma repetição no tempo de açôes, por outro lado, eles não se confundem com os comportamentos, pois a ideia do hábito não pode ser restrita ao domínio individual, uma vez que o indivíduo, ao ser inserido na cultura, é atravessado por disposiçóes que deixam marcas indeléveis. Essa diferenciação não é simples, nem dispensável. No campo da Alimentação e Nutrição, entretanto, parece haver, segundo as autoras, um uso indistinto desses termos, o que acarreta importantes imprecisóes teóricas e dificuldades práticas.

Assim, no campo da saúde assistimos ao crescimento do interesse por abordagens que tenham em seu fundamento a mudança de comportamento, já que um dos grandes problemas enfrentados pelos nutricionistas e outros profissionais de saúde é a baixa adesão à modificação de hábitos alimentares relacionados ao desenvolvimento de DCNTs (ESTRELA et al., 2017). No Brasil, seguindo recomendaçóes de entidades internacionais como a Organização Mundial da Saúde (WHO, 2018) e a Organização Pan-americana da Saúde (OPAS, 2018), têm se tornado um imperativo para prevenção e tratamento das DCNTs o investimento em medidas que têm como alvo a promoção de mudanças ambientais que dificultem o consumo de alimentos ultraprocessados ${ }^{1}$ pobres em nutrientes e recheados de aditivos químicos. A publicação em 2014 da nova versão do Guia Alimentar para a População Brasileira (BRASIL, 2014a) possui papel importante nesse processo por considerar a promoção da alimentaçáo adequada e saudável como parte da construção de um sistema alimentar social e ambientalmente sustentável e por ressaltar condicionantes da alimentação, desde a produção do alimento até seu consumo. Suas recomendaçôes baseiam-se em uma classificaçáo de alimentos segundo o grau de processamento, indicando que seja limitado o consumo de alimentos processados e evitado o consumo de ultraprocessados. Há, entretanto, o reconhecimento de que a ampliação e consolidação de tais medidas só são possíveis com a implementação de políticas públicas que tenham como intuito transformar os ambientes obesogênicos, como a regulamentação da publicidade de alimentos e taxação de alimentos ultraprocessados (MONTEIRO et al., 2010; BRASIL, 2014a). Essas iniciativas têm como alvo não 
somente a indústria de alimentos, mas também a mídia e seu potencial de influência nas escolhas e hábitos da população (BRASIL, 2014b).

Essas iniciativas seguem o que Dolan et al. (2012) nomeiam como estratégias que visam mudar contextos e acompanham uma tendência internacional das políticas públicas em Alimentação e Nutrição, em detrimento de mudar ideias, que seria mais usual na busca da mudança comportamental. Os autores argumentam que enquanto esta última abordagem se baseia em informaçóes conscientes e fundamenta-se em processos, a primeira lida predominantemente com o sistema automatizado subconsciente do cérebro, tentando facilitar a mudança ao alterar o contexto ambiental no qual as pessoas tomam decisóes. De qualquer modo, o que fica patente nesse e em outros artigos mais recentes é a grande dificuldade que se coloca aos estudiosos do comportamento quando é preciso efetuar mudanças (TEIXEIRA, 2016; BULL et al., 2014). Kelly e Barker (2016) apontam que todo problema reside no fato de que se buscam respostas simples e não científicas para problemas complexos.

Nesse sentido, saindo da simplicidade com que costumamos tratar as questôes comportamentais no campo da Alimentação e Nutrição, podemos considerar que a própria definição de comportamento é por si só problemática, pois se a afirmação corrente de que "o comportamento é a interação entre o organismo e o ambiente" (TORODOV, 2012, p. 33) for tratada de forma mais rigorosa, veremos que a ampliação de sua definição expóe sua limitação a ponto de torná-la indefinida. Isto quer dizer que à medida que o comportamento é um tipo de interação dentre vários outros tipos de interaçôes que se dão entre organismo e ambiente, causando alteraçôes em ambos, depreende-se daí que qualquer interação que o organismo realiza com seu meio ambiente são interaçôes que envolvem alguma alteração no organismo com alguma alteração no ambiente. Essas interaçôes, contudo, não são necessariamente comportamentos (TODOROV, 2012). Nesse sentido, não seria demasiado simples identificar comportamento com interação? E ainda, dada a complexidade da definição do comportamento, como isolá-lo dos demais fatores e conhecê-lo de modo exaustivo?

Numa perspectiva médica ou neurocientífica, outra definição igualmente problemática é apresentada por Michie et al. (2014), segundo a qual o comportamento é entendido como "qualquer ação de um indivíduo que responda a eventos internos ou externos” (p. 36). Apesar da conceituação demasiado abrangente, os autores 
propõem uma subdivisão dessas açôes que engloba por um lado as açôes explícitas que podem ser motoras ou verbais e de outro as açóes implícitas que corresponderiam a atividades não visíveis envolvendo musculatura voluntária. Em suma, para os autores, os "comportamentos são eventos físicos que ocorrem no corpo e são controlados pelo cérebro" (p. 36). Nesse sentido, os comportamentos ficam atrelados à sua dimensão mensurável, localizável e controlável ancorados na concretude cerebral, livres em sua definição de qualquer interação com o contexto em que se dão. Ora, uma ação é sempre dependente de vários elementos corporais, assim como do ambiente em que se desenrola, onde promove seus efeitos e consequências. Depreende-se daí um primeiro questionamento acerca da necessidade extrema de isolar os comportamentos, restringindo-os a uma mecânica biologicista: a que serve esse ideal científico exacerbado que priva o entendimento de toda complexidade que lhe é própria?

\section{Motivação e mudança: duas faces de uma moeda}

Para dar conta de entender as necessidades conceituais das teorias comportamentais inscritas no campo da Psicologia da Saúde, Ogden (2016) interroga se há um limite para a sistematização de teorias e técnicas ligadas às mudanças comportamentais e, consequentemente, dos modelos de comportamento. Destaca que nesse campo teórico a variabilidade deve ser festejada e não removida como se fosse algo reprovável e indesejável. Para chegar a essa polêmica afirmação, Ogden faz um instigante percurso no qual destaca as diversas nuances dessa variabilidade: para a Medicina ela assume a forma do comportamento do profissional de saúde, para a Educação é o estilo e o conteúdo dado em sala de aula que é sempre muito variável, enquanto para a Psicologia da Saúde a variabilidade pode ser encontrada tanto no comportamento do paciente, quanto nas teorias usadas e até mesmo na própria prática clínica.

Segundo Ogden (2016), as soluçôes relacionadas à educação em saúde adotadas até recentemente para problemas relacionados diretamente ao aumento das DCNTs - tais como a persistência de grande parte dos pacientes em manter dietas precárias, o contínuo aumento do número de casos de obesidade em todo o mundo, o tabagismo, o sedentarismo e a baixa adesão aos tratamentos - indicam que o conhecimento por si só não se traduz em ações efetivas (DEBUSSCHE, 2014). Além disso, estudos indicam que há grande dificuldade em efetuar e manter as mudanças de comportamentos inadequados, ressaltando as dificuldades teóricas e práticas enfrentadas pelos 
profissionais de saúde na promoção de hábitos saudáveis (PRESTWICH et al., 2014; CONNER; NORMAN, 2015; KWASNICKA et al., 2016).

Para preencher essa lacuna, foram desenvolvidas estratégias apoiadas em teorias motivacionais propondo-se tarefas de autoafirmação, planejamento e implementação de metas de mudança que funcionam até certo ponto. Entretanto, o problema da variabilidade dos pacientes mostrou-se complicado, o que fica explícito na subsequente publicação de artigos, demonstrando que o comportamento só pode ser alterado para algumas pessoas durante algum tempo e não por muito tempo, muito menos definitivamente (HARTMANN-BOYCE et al., 2013; BULL et al., 2014). Estudos ressaltam ainda que o contexto tem influência direta na mudança de comportamentos e em sua manutenção, assim como um contexto estável tende a ser favorável para o início de um processo de mudança (KWASNICKA et al., 2016).

Foi em 2008, porém, que a Behaviour Change Technique Taxonomy ${ }^{2}$ foi proposta por um grupo de pesquisadores (ABRAHAM; MICHIE, 2008; MICHIE et al., 2011; 2013; MICHIE; WOOD, 2015) e se tornou um empreendimento multidisciplinar de enorme sucesso. Esta proposta tinha como objetivos: 1) codificar protocolos como meio de descrever e sistematizar técnicas de mudança comportamental, para que os protocolos pudessem ser mais claros e os estudos pudessem ser replicados e 2) usar esse exercício de codificação para produzir uma taxonomia que, por sua vez, poderia ser usada para identificar quais técnicas são mais eficazes. Em tese esse esforço maximizaria a eficácia das intervençóes, os pacientes mudariam seu comportamento e o problema da variabilidade dos pacientes seria definitivamente resolvido.

Contudo, Ogden (2016) identificou que entre aquilo que um protocolo pode realmente prever e codificar e o que as pessoas de fato fazem existem muitas lacunas: primeira e fundamentalmente há uma lacuna entre as crenças do paciente e seu comportamento, mas também entre o comportamento do paciente e o do profissional de saúde, entre o comportamento do profissional de saúde e suas próprias crenças sobre como agir com o paciente, entre essas crenças e o treinamento que receberam para executar determinada intervenção, entre o protocolo e o treinamento feito com base nele e, por fim, entre o protocolo em si e aquele que o codificou. O que há na verdade é um imenso abismo entre o protocolo e o comportamento do paciente propriamente dito.

No que diz respeito à variabilidade da teoria, Ogden (2016) ressalta que nos últimos 50 anos, foram desenvolvidas, testadas e aplicadas uma série de teorias que 
incluem tanto perspectivas amplas quanto modelos mais específicos, e dá destaque para um modelo integrado que transformou a pesquisa nos últimos anos: o COM-B. Com foco na Capacidade, Oportunidade e Motivação e na Roda de Mudança de Comportamento apresentados em pesquisas capitaneadas por Michie, esse modelo visa reduzir a variabilidade da teoria e identificar uma abordagem sistematizada integrada que transcenda as perspectivas individuais e possa ser aplicada a todos os comportamentos. Ao mesmo tempo que Ogden reconhece que essa admirável tentativa reflete a necessidade de apresentar uma visão simplificada e precisa dos processos que sustentam o comportamento em saúde (HAGGER, 2009 apud OGDEN, 2016), ela interroga em que medida essa simplificação promove e facilita a criatividade dos que pensam nesses desafios.

Para a autora, esse percurso denuncia que aspectos teóricos e técnicos privilegiados por saberes hegemônicos acabam por construir verdadeiras caixas-pretas cujo grau de verdade é inquestionável (LATOUR, 1987) e que, no limite, impossibilitam o próprio avanço científico. Trata-se na verdade de uma impossibilidade característica dos paradigmas científicos que tendem a marginalizar ideias que desafiam visôes dominantes ou grupos de pesquisa que tentam apresentar perspectivas opostas (OGDEN, 2002). Nesse sentido, promover a variabilidade da teoria é o que permite que os cientistas permaneçam livres, independentes e criativos, e não a mensuração e o controle extremo que vem sendo exigido e valorizado no campo científico. Da mesma maneira, a autora defende que a variabilidade das ferramentas utilizadas na prática pelos profissionais de saúde garante a aliança terapêutica onde a flexibilidade, variabilidade e mudança de acordo com o tipo de comportamento, o tipo de intervenção ou mesmo o tipo de paciente podem ser exercitadas. Para Ogden, se removermos essa variabilidade e sistematizarmos uma polegada de nossas vidas, não seremos mais profissionais, mas sim técnicos.

\section{A Nutrição neoliberal: aprisionamento travestido em discurso libertador}

Os argumentos e elementos teóricos percorridos desafiam a (re)conhecer e aprofundar aspectos relevantes que têm sido resumidos ou omitidos na apresentação de abordagens comportamentais no campo na Alimentação e Nutrição. Dentre as reflexôes necessárias, duas se colocam como primordiais: a que servem tais abordagens e para onde elas nos levam? 
Essas perguntas localizam elementos que vinculam processos e práticas em curso no campo da Alimentaçáo e Nutrição ao contexto histórico atual no qual os efeitos socioculturais relacionados à consolidação das sociedades capitalistas não nos permitem ver com clareza as estratégias de poder e controle que impactam inevitavelmente no discurso científico. O título do presente artigo faz alusão direta à expressão "fábrica do sujeito neoliberal" proposta por Dardot e Laval (2016), que busca nomear o modo de produçáo das subjetividades que não escapam aos efeitos deletérios do neoliberalismo e que se pulverizam em diversos dispositivos de controle e autocontrole. Da mesma maneira, buscamos indicar aqui como esses efeitos impactam a nutrição promovendo novas e perigosas abordagens que vêm sendo amplamente propagadas no campo da saúde.

De acordo com Purser, em seu livro McMindfulness: How the mindfulness became the new capitalist spirituality (2019), o Mindfulness (ou Atenção Plena, como é chamado no Brasil) é somente um treinamento básico de concentração, mas que tem sido vendido como um produto que tem o potencial de desencadear uma revolução global. Entretanto, essa ferramenta de autodisciplina disfarçada de autoajuda, ao invés de dar ao praticante a desejada liberdade, fornece na verdade as condiçóes que o levam ao seu aprisionamento dentro de um sistema estruturado. Relacionando essa estratégia ao contexto do trabalho onde a prática de Mindfulness vem sendo amplamente usada no manejo do estresse dos trabalhadores, Purser (2019), sustenta a ideia de que o propalado potencial revolucionário do Mindfulness, ofusca a lógica capitalista implícita nessa prática: a meditação fast-food acaba por colaborar para a efetivação das formas mais graves de exploração dos trabalhadores, dizendo-lhes que o estresse é algo que cada um deve lidar individualmente, esvaziando as esferas coletivas de resistência à alienação do trabalho e subjetiva. Tais práticas - que vêm sendo implementadas nas empresas, mas também em diversos âmbitos da vida cotidiana e que se inserem na chamada "Mindfulness Revolution" (p. 7) - nada mais são do que meros instrumentos do mercado que visam, com seu ethos terapêutico, aprimorar a resiliência dos indivíduos, endossando ao mesmo tempo os pressupostos neoliberais de que todos são livres para escolher seus caminhos, gerenciar emoçôes negativas e florescer utilizando várias formas de cuidar de si.

Assim como qualquer nova dieta que aparece no verão, essas abordagens se vendem com uma aparência de cientificidade para ganhar credibilidade, mas as evidências científicas de sua eficácia deixam muito a desejar. Vale ressaltar que o 
Mindfulness já movimentou uma indústria de quatro bilhôes de dólares nos Estados Unidos (PURSER, 2019), abrangendo venda de livros e cursos presenciais e à distância que englobam variedades que vão desde o Mindful Parenting, Mindful Teaching, Mindful Leadership, Mindful Finance, Mindful Dog Owners até o Mindful Eating, que se tornou, curiosamente, popular entre os nutricionistas brasileiros sob o nome "Comer com Atenção Plena".

Considerada uma das técnicas da Nutrição Comportamental ${ }^{\circ}$ (ALVARENGA et al., 2019), o Mindful Eating se propagou rapidamente entre os nutricionistas, pois despontou como um recurso inovador para lidar com a ansiedade no contexto da dita epidemia global de obesidade. Segundo Bays (2009 apud ALVARENGA, 2019, p. 260), trata-se de uma:

[...] experiência que engaja todas as partes do nosso ser - corpo, mente e coração - na escolha e preparo da comida, bem como no ato de comê-la em si. Envolve todos os sentidos. O comer com atenção plena nos imerge nas cores, texturas, aromas, sabores e até mesmo sons do comer e beber. Permite que sejamos curiosos e até lúdicos enquanto investigamos nossas respostas à comida e nossos sinais internos de fome e saciedade.

Destaca-se dessa definiçáo o tom pacificador que faz com que se acalmem sentimentos individuais gerados pela vida cotidiana por meio do resgate de aspectos da comida e do comer que não se encaixam na correria e urgência característicos da sociedade contemporânea. Esse caráter conciliador que a prática do Mindfulness promoveria, entretanto, desvia o olhar das desigualdades sociais, políticas e econômicas que inevitavelmente causam o estresse e a ansiedade a grande parte da população brasileira e que se relacionam, em última análise, com o crescimento dos casos de sobrepeso e obesidade, mas também da fome e da desnutrição. Essas causas que se vinculam diretamente ao modo de produção capitalista ficam minimizadas e toda responsabilidade recai sobre o indivíduo que deve encontrar formas de realizar as orientaçóes, tornando-se uma pessoa com ampla capacidade de autocontrole.

Essa estratégia de psicologização e de privatização da religiosidade (CARRETTE; KING, 2005 apud PURSER, 2019) atreladas ao Mindfulness é política. Melhor dizendo, essa estratégia, como muitas outras, equivale ao que Han (2018) nomeia como Psicopolítica. Ou seja, trata-se de novos dispositivos de poder próprios ao neoliberalismo que exploram o indivíduo a tal ponto que o submete a si mesmo e a seu desempenho. Nessa linha, Dardot e Laval (2016) consideram que o empreendedorismo de si é alimentado por um regime concorrencial que exige a todo momento que o indivíduo 
seja o melhor, ou ainda, que ultrapasse até mesmo seus próprios limites, impondo uma nova norma subjetiva. Desse modo, o sistema neoliberal teria enfraquecido as tradicionais formas de ação coletiva à medida que os indivíduos estão submetidos a um regime de concorrência que opera em todos os níveis.

Vale destacar que os dispositivos em jogo na fabricaçáo desse sujeito neoliberal ultrapassam as disciplinas clássicas que operavam pela coerção, pelo adestramento e docilização dos corpos (FOUCAULT, 1988; 2000), e levam o indivíduo a envolverse completamente com a tarefa que lhe é exigida. Esse sujeito neoliberal é o sujeito do envolvimento total de si mesmo, da racionalização do desejo que passa a ser cooptado pelos dispositivos de poder que se tornam parte do próprio sujeito.

Desse modo, injunge-se o sujeito a conformar-se intimamente, por um trabalho interior
constante, à seguinte imagem: ele deve cuidar constantemente para ser o mais eficaz pos-
sível, mostrar-se inteiramente envolvido no trabalho, aperfeiçoar-se por uma aprendiza-
gem contínua, aceitar a grande flexibilidade exigida pelas mudanças incessantes impostas
pelo mercado. Especialista em si mesmo, empregador de si mesmo, inventor de si mesmo,
empreendedor de si mesmo: a racionalidade neoliberal impele o eu a agir sobre si mesmo
para fortalecer-se e, assim, sobreviver na competiçáo (DARDOT; LAVAL, 2016, p. 330).

Essa mesma lógica em curso no campo do trabalho pode ser a chave de entendimento dessas novas abordagens na Alimentação e Nutrição. Pois, assim como o Mindful Eating exige o engajamento de todas as partes do nosso ser e a total concentração no que se come, onde se come e como se come, a Nutrição Comportamental $^{\circ}$ (ALVARENGA et al, 2019) propóe a mudança real e consistente do comportamento alimentar por meio de técnicas de automonitoramento e autocontrole. Da mesma maneira, o Comer Intuitivo propóe-se a ensinar o indivíduo a diferenciar a fome física da fome emocional e sugere que o comer deve acontecer de acordo com as sensaçôes de fome, apetite e saciedade.

Ora, essa é uma antiga discussão filosófica que não cabe retomar aqui neste ensaio, mas vale lembrar que a distinçâo segura e garantida entre o físico e o emocional nunca foi delimitada, restando tão somente o esforço hercúleo de racionalizar cada passo, cada desejo e cada mordida para poder restringir aquilo que é determinado pela norma vigente como o que se deve ou não se deve comer. Assim, alimentar-se por razóes físicas garantiria o prazer associado que não estaria presente na alimentação por razôes emocionais. A estratégia de resgate da intuição, tâo valorizada por povos ancestrais, é capturada por meio de uma espécie de sabedoria corporal que, com devido treinamento, torna os praticantes "experts do próprio corpo" (ALVARENGA; 
FIGUEIREDO, 2019, p. 228). Se por um lado a proposta atende aos apelos neoliberais de conformaçáo do indivíduo à norma, a mesma náo proporciona um prazer nem liberta os indivíduos da propagada mentalidade da dieta.

Vigiar-se a si mesmo, controlar-se a si mesmo, entender-se a si mesmo e meditar, essa é a ética do nosso tempo. Essa ética neoliberal que alicia as subjetividades não permite nenhuma liberdade: o domínio exacerbado de si aparece como a contrapartida de uma situação global incontrolável (DARDOT; LAVAL, 2016). A liberdade é a moeda de troca, o tesouro perdido, o santo Graal almejado e desejado por todos. É ela que, mesmo elidida das relaçóes sociais, captura corações e mentes. Onde ela está? Certamente a lógica comportamental que circula no campo da Alimentação e Nutrição promete uma liberdade para aquele que se livra dos problemas relacionados à alimentaçáo, à tortura das dietas e do desconforto com o corpo, mas o que ela entrega é, na verdade, uma outra prisão. A lógica do controle extremo não favorece a emergência da liberdade. Pelo contrário. A estratégia de responsabilização do indivíduo por si mesmo obriga cada um a responder por seu comportamento a partir de padronizações que são externas ao sujeito.

Aoresponsabilizarsobremaneiraoindivíduo, decertoestamosdesresponsabilizando outros como o Estado e as políticas públicas. A liberdade, nesse contexto, está conjugada com o poder, ele se serve dela uma vez que é ela quem entrega os sujeitos na bandeja para a máquina capitalista. O sujeito, em nome da liberdade, se entrega de corpo, mente e alma ao que se quer fazer dele, exigindo de si mesmo que produza sempre mais, deseje sempre mais e atinja sempre o máximo, mais além do equilíbrio outrora desejado.

\section{Últimas considerações}

E assim, mais uma vez, estamos diante de refinados mecanismos de controle que têm como foco o comportamento. Mas o sujeito em sua essência é rebelde e não se deixa dominar facilmente. A variabilidade com que cada indivíduo se apresenta nos consultórios nas clínicas de família, nos hospitais, nos locais de trabalho é o testemunho da resistência que se desdobra a cada nova tentativa de dominação e padronização. Apostar como tiro certeiro que essas abordagens são a salvação para os desafios e impasses ligados à nutrição é colocar a perder todo esforço e investimento que vem sendo feito pelo campo científico da Alimentação e Nutrição 
em sua abertura polifônica a outros discursos e saberes. Se há inovação neste campo, ela não é simples e não depende da incorporação simplista de uma nova técnica que não conhecemos com uma oratória bem trabalhada por marqueteiros reconhecidos. Conhecemos as dificuldades cotidianas dos profissionais de saúde no cuidado a pessoas com sobrepeso e obesidade, por exemplo, mas também em tantos outros agravos à saúde. Reconhecemos os limites e dificuldades da nossa atuação. Só nos falta criar algo que não esteja a serviço da servidão voluntária dos indivíduos.

A crítica aqui delineada em relação às novas abordagens no campo da Alimentação e Nutrição nos remete ao que propóe Agamben em seu "Elogio da profanação" (2007). Assim como uma religiáo que subtrai coisas, lugares ou pessoas ao uso comum transferindo-as a outra esfera, o dispositivo biomédico desloca o corpo e a alimentação para a esfera do sagrado, subtraindo aí o uso que se pode fazer deles e delegando aos experts (cada vez mais espertos) a tarefa de criar, publicizar e vender as normas e regras a que os sujeitos devem se identificar e, partir daí, desejar.

As teorias comportamentais, as religiōes orientais e as técnicas motivacionais, ao serem incorporadas pelas práticas e teorias nutricionais de forma simplificada reiteram, de modo velado e ingênuo, mecanismos de dominação social que se expressam nessa busca desenfreada por uma saúde plena que aponta uma supernormalidade (NEVES et al., 2015). A restituição da possibilidade de criar regras para si que comportem alguma liberdade ou alguma separação em relação à sujeição neoliberal passa necessariamente por certa negligência, onde se pode desejar algo que não seja mais além do máximo. Nas palavras de Agamben, "é importante arrancar dos dispositivos - de todo dispositivo - a possibilidade de uso que os mesmos capturam. A profanação do Improfanável é a tarefa da geração que vem” (2007, p. 79). Se há alguma liberdade, ela está no resgate do desejo com todos os riscos de perdas e falhas que o constituem. ${ }^{3}$

\section{Referências}

ABRAHAM, C.; MICHIE, S. A taxonomy of behavior change techniques used in interventions. Health Psychol, v. 27, n. 3, p. 379-87, 2008. doi: 10.1037/0278-6133.27.3.379.

AGAMBEN, G. Elogio da profanação. In: . Profanaçôes. São Paulo, Boitempo, 2007. p. 65-79.

ALVARENGA, M. S.; FIGUEIREDO, M. Comer Intuitivo. In: ALVARENGA, M. S. et al. (Orgs.). Nutrição Comportamental. 2. ed. Barueri: Manole, 2019. p. 227-256. 
ALVARENGA, M. S. et al. (Orgs.). Nutrição Comportamental. 2. ed. Barueri: Manole, 2019.

BAUMAN, Z. Modernidade líquida. Rio de Janeiro: Jorge Zahar, 2001.

BAYS, J. C. Mindful eating: a guide to discovering a healthy and joyful relationship with food. London: Shambala, 2009.

BRASIL. Ministério da Saúde. Perspectivas e desafios no cuidado as pessoas com obesidade no SUS: resultados do Laboratório de Inovação no manejo da obesidade nas Redes de Atenção à Saúde. Brasília: Ministério da Saúde, 2014b.

. Ministério da Saúde. Secretaria de Atenção à Saúde. Departamento de Atenção Básica. Guia alimentar para a população brasileira. Brasília: Ministério da Saúde, 2014a.

BULL, E. R. et al. Are interventions for low-income groups effective in changing healthy eating, physical activity and smoking behaviours? A systematic review and meta-analysis. BMJ Open, v. 4, n. 11, e006046, 2014. Doi: http://dx.doi.org/10.1136/bmjopen-2014-006046.

CARRETTE, J.; KING, R. Selling spirituality: The silent takeover of religion. London: Routledge, 2005.

CONNER, M. T.; NORMAN, P. Predicting health behaviour: research and practice with social cognition models. London: Open University Press, 2015.

DARDOT, P.; LAVAL, C. A nova razão do mundo: ensaio sobre a sociedade neoliberal. São Paulo: Editora Boitempo, 2016.

DARNTON, A. Reference Report: an overview of behavioural change models and their uses. Government Social Research Unit: London, July 2008. Disponível em: <https:// research.fit.edu/media/site-specific/researchfitedu/coast-climate-adaptation-library/climatecommunications/messaging-climate-change/Darnton.-2008.-Behaviour-Change-Models-Uses.pdf>. Acesso em: 27 mar. 2020.

DEBUSSCHE, $\mathrm{X}$. Is adherence a relevant issue in the self-management education of diabetes? A mixed narrative review. Diabetes Metab Syndr Obes, v. 7, p. 357-67, 2014. doi: 10.2147/ DMSO.S36369.

DOLAN, P. et al. Influencing behaviour: the mindspace way. Journal of Economic Psychology, v. 33, n. 1, p. 264-77, 2012. doi: https://doi.org/10.1016/j.joep.2011.10.009.

ESTRELA, K. C. A. et al. Adesão às orientações nutricionais: uma revisão de literatura. Demetra, v. 12, n. 1, p. 249-274, 2017. doi: https://doi.org/10.12957/demetra.2017.22407.

FOUCAULT, M. O nascimento da clínica. Rio de Janeiro: Forense Universitária. 1994. . História da Sexualidade 1: A vontade de saber. Rio de Janeiro: Edições Graal, 1988. . Em defesa da sociedade. São Paulo: Martins Fontes, 2000. 
FREUD, S. Dos verbetes de enciclopedia: "Psicoanálisis" y “Teoria de La libido" [1923]. In: Obras Completas. Buenos Aires: Amorrortu, 2006.

HAGGER, M. S.; CHATZISARANTIS, N. L. Integrating the theory of planned behaviour and self-determination theory in health behaviour: a meta-analysis. Br J Health Psychol, v. 14, n. Pt 2, p. 275-302, 2009. doi: 10.1348/135910708X373959.

HAN, B-C. Psicopolitica: o neoliberalismo e as novas técnicas de poder. Belo Horizonte: Edtora Âyiné, 2018.

HARTMANN-BOYCE, J. et al. Managing overweight and obese adults: update review. The clinical effectiveness of long terms weight management schemes for adults. Oxford: University of Oxford, 2013. Disponível em: <https://www.nice.org.uk/guidance/ph53/evidence/evidencereview-1a-431707933>. Acesso em: 27 de março de 2020.

KELLY, M. P.; BARKER, M. Why is changing health related behavior so difficult? Public Health, v. 136, p. 109-116, 2016. http://dx.doi.org/10.1016/j.puhe.2016.03.030.

KLOTZ-SILVA, J.; PRADO, S. D.; SEIXAS, C. M. Comportamento alimentar no campo da Alimentação e Nutrição: do que estamos falando? Physis, v. 26, n. 4, p. 1103-1123, out. 2016. doi: https://doi.org/10.1590/s0103-73312016000400003.

KUHN, T. The structure of scientific revolutions. Chicago: Chicago University Press, 1962.

KWASNICKA, D. et al. Theoretical explanations for maintenance of behaviour change: a systematic review of behaviour theories. Health Psychology Review, v. 10, n. 3, p. 277-296, 2016. doi: 10.1080/17437199.2016.1151372.

LATOUR, B. Science in Action. Harvard University Press: Cambridge, 1987.

MICHIE, S. et al. A refined taxonomy of behaviour change techniques to help people change their physical activity and healthy eating behaviours: the CALO-RE taxonomy. Psychol Health, v. 26, n. 11, p. 1479-98, 2011.

MICHIE, S. et al. ABC of Behaviour Change Theories. Reino Unido: Silverback Publishing, 2014. . The behavior change technique taxonomy (v. 1) of 93 hierarchically clustered techniques: building an international consensus for the reporting of behavior change interventions. Ann Behav Med, v. 46, n. 1, p. 81-95, 2013. doi: 10.1007/s12160-013-9486-6.

MICHIE, S.; WOOD, C. E. Health behaviour change techniques. In: CONNER, M.; NORMAN, P. (eds). Predicting and changing health behaviour. Research and practice with social cognition models. McGraw Hill: New York. 2015, p. 358-389.

MONTEIRO, C. A. Nutrition and health. The issue is not food, nor nutrients, so much as processing. Public Health Nutr, v. 12, n. 5, p. 729-31, 2009. doi:10.1017/S1368980009005291. 
MONTEIRO, C. A. et al. A new classification of foods based on the extent and purpose of their processing. Cad Saúde Pública, v. 26, p. 2039-49, 2010. doi: https://doi.org/10.1590/S0102$311 \mathrm{X} 2010001100005$.

MORIN, E. Introdução ao pensamento complexo. Porto Alegre: Editora Sulina, 2011. A via para o futuro da humanidade. Rio de Janeiro: Bertrand Brasil, 2013.

. A cabeça bem-feita: repensar a reforma, reformar o pensamento. Rio de Janeiro: Bertrand Brasil, 2014.

MOSS, M. Sal, açúcar e gordura: como a indústria alimentícia nos fisgou. Rio de Janeiro: Intrínseca, 2015.

NEVES, A. et al. A nutrição na busca pela supernormalidade. In: PRADO, S. D. et al. (Orgs.). Alimentação e consumo de tecnologias. 1ed. Curitiba: CRV, 2015, p. 93-116.

OGDEN, J. Health and the construction of the individual. Routledge: London, 2002.

. Celebrating variability and a call to limit systematisation: The example of the behaviour change technique taxonomy and the behaviour change wheel. Health Psychology Review, v. 10, n. 3, 2016, p. 245-250. doi:10.1080/17437199.2016.1190291.

ORGANIZAÇÃO PANAMERICANA DE SAÚDE. Alimentos e bebidas ultraprocessados na América Latina: tendências, efeito na obesidade e implicações para políticas públicas. Brasília, DF, 2018.

POLLAN, M. O dilema do onivoro: uma história natural das refeiçôes. Rio de Janeiro: Intrínseca, 2007.

POULAIN, J. P. Sociologia da obesidade. São Paulo: Editora Senac São Paulo, 2013.

PRADO, S. D.; MARTINS, M. L. R.; CARVALHO, M. C. V. S. A pesquisa no campo da Alimentação e Nutrição no Brasil: pluralidade epistêmica e produtividade científica. Rio de Janeiro: Gramma/Eduerj, 2018.

PRESTWICH, A. et al. Does theory influence the effectiveness of health behavior interventions? Meta-analysis. Health Psychology, v. 33, n. 5, p. 465-474, 2014. doi: 10.1037/a0032853.

PURSER, R. McMindfulness: how the mindfulness became the new capitalist spirituality. New York: Repeater, 2019.

TEIXEIRA, P. Health behavior change: a field just picking up speed. A comment on Ogden. Health Psychol Rev, v. 10, n. 3, p. 269-73, set 2016. doi: 10.1080/17437199.2016.1183507.

TODOROV, J. C. Sobre uma definição de comportamento. Perspectivas, v. 3, n. 1, p. 32-37, 2012. VAN DER LINDEN, S. A response to Dolan. In: OLIVER, A. J. (Ed.). Behavioural Public Policy. Cambridge: Cambridge University Press, 2013, p. 209-215. Disponível em: <https:// scholar.princeton.edu/sites/default/files/slinden/files/dolan.pdf> Acesso em: 27 mar. 2020. 
VASCONCELOS, F. A. G. O nutricionista no Brasil: uma análise histórica. Rev. Nutr. v. 15, n. 2, p. 127-138, 2002.

WORLD HEALTH ORGANIZATION. NCD Country Profiles, 2018. Disponível em <https:// www.who.int/nmh/publications/ncd-profiles-2018/en/>. Acesso em: 27 mar. 2020.

\section{Notas}

${ }^{1}$ Segundo Monteiro (2009), os alimentos ultraprocessados são formulaçôes industriais prontas para consumo e feitas inteira ou majoritariamente de substâncias extraídas de alimentos (óleos, gorduras, açúcar, proteínas), derivadas de constituintes de alimentos (gorduras hidrogenadas, amido modificado) ou sintetizadas em laboratório com base em matérias orgânicas (corantes, aromatizantes, realçadores de sabor e outros aditivos usados para alterar propriedades sensoriais).

${ }^{2}$ Taxonomia das Técnicas de Mudança de Comportamento (tradução nossa).

${ }^{3}$ C. M. Seixas: concepção e coordenação da pesquisa, redação do artigo e revisão final do artigo. J. P. Casemiro, C. O. Coutinho e T. N. Conde: concepção da pesquisa e redação do artigo. A. L. Brandão: revisão crítica do conteúdo intelectual. 


\section{Abstract}

\section{Neoliberal nutrition factory: elements to discuss new behavioral approaches}

The application of behavioral theories in several areas has aroused the interest in investigating how these theories are incorporated by the field of Food and Nutrition, problematizing its interdisciplinarity. This paper aims to contextualize Nutrition as a science and its development in a social context in which neoliberalism operates as a system for managing political, economic, and social life. The aim is to gather theoretical elements related to the notion of behavior extracted from the field of Psychology in order to contribute to the deepening of reflections on the emergence of techniques based on theories of behavior, such as Behavioral Nutrition, Mindful Eating and Intuitive Eating, in addition to presenting considerations on the limits related to the application of these approaches in the training and practice of health professionals.

> Keywords: Behavioral Nutrition; Mindful Eating; Intuitive Eating; neoliberalism; interdisciplinarity. 


\section{ERRATA}

No artigo "Fábrica da nutriçâo neoliberal: elementos para uma discussão sobre as novas abordagens comportamentais", com número de DOI: http://dx.doi. org/10.1590/S0103-73312020300411 publicado no periódico Physis: Revista de Saúde Coletiva, v. 30, n. 4, e300411, na página 1, erro de nome de autor:

ONDE SE LÊ:

Cristiane Marques Seixa

LEIA-SE:

Cristiane Marques Seixas 